\title{
Epidemiological and clinical characteristics of COVID-19 in Indian children in the initial phase of the pandemic: A cross-sectional study
}

\section{Bhakti Sarangi}

Bharati Vidyapeeth Medical College, Pune

\section{Venkat Sandeep Reddy}

Bharati Vidyapeeth Medical College, Pune

Jitendra S. Oswal ( jsoswal@gmail.com )

Bharati Vidyapeeth Medical College, Pune

\section{Nandini Malshe}

Bharati Vidyapeeth Medical College, Pune

\section{Ajinkya Patil}

Bharati Vidyapeeth Medical College, Pune

Manojit Chakraborty

Bharati Vidyapeeth Medical College, Pune

\section{Sanjay Lalwani}

Bharati Vidyapeeth Medical College, Pune

\section{Research Article}

Keywords: COVID-19, pandemic, children, epidemiology, SARS-CoV-2, RT-PCR

Posted Date: June 19th, 2020

DOI: https://doi.org/10.21203/rs.3.rs-36303/v1

License: (9) (i) This work is licensed under a Creative Commons Attribution 4.0 International License. Read Full License 


\section{Abstract}

Background: India saw the largest and the most stringent lockdown in the world when the number of COVID-19 cases reached around 550. With some early benefits in containing the surge and restricting the $\mathrm{R} 0$ of the virus, the current relaxation of lockdown norms has witnessed an exponential rise in positive cases. With scarcity of Pediatric data from the Indian subcontinent, early observations in the pandemic are pivotal in improving the understanding of physiologic behaviors, identifying risks, and guiding clinicians in assessing time-tested interventions and augmenting the awareness in the masses about the manifold clinical profiles of an evolving disease.

Objective: To assess the epidemiological and clinical characteristics of children admitted with COVID-19 infection early in the pandemic.

Study Design: A cross-sectional study

Participants: Fifty children between one month and 18 years of age whose nasopharyngeal swab tested positive for SARS-CoV-2 by RT- PCR.

Results: 28 (56\%) children were male. 41 (82\%) came from government declared containment zones with only one child having history of travel to affected area. Home overcrowding was observed in $33(66 \%)$. Of the 50 children, 29 (58\%) were asymptomatic while 20 (40\%) and one (2\%) had mild and moderate symptoms respectively. Fever, cough, and sore throat were the most common symptoms. 49 (98\%) children had BCG scar. Leucopenia was seen in three (6\%) only. Mean (SD) Neutrophil-Lymphocyte-Ratio (NLR) was 0.78 (0.48) while mean (SD) CRP was 10.98 (23.90). All 50 (100\%) were cured.

Conclusion: Our study reasserts the increasing pediatric burden of COVID-19 with all age groups affected and overcrowding as a risk factor for continued community transmission, thus beckoning that public health policies be directed to ensuring further preventive measures. It also re-iterates the milder disease pattern in children with COVID-19 in the initial phase of the pandemic with a high proportion of asymptomatic and mild illness. Though abnormal CRP values are synonymous with the illness in children; leucopenia may not be a consistent finding.

\section{Introduction:}

Coronaviruses have long been known as a group of viruses that cause diseases in mammals and birds. Enveloped with positive-sense single-stranded RNA, they cause respiratory and gastrointestinal symptoms ranging from common cold to more severe disease such as pneumonia, acute respiratory distress syndrome (ARDS), and multi-organ dysfunction in humans. Coronaviruses are capable of recombinations and rapid mutations leading to newer coronaviruses. The COVID-19 is one such infectious disease caused by severe acute respiratory syndrome coronavirus 2 (SARS-CoV-2) which is currently causing outbreaks globally. 
The first infection caused by the SARS-CoV-2 was recorded in November 2019 from Wuhan, Hubei Province, China. This airborne infection spread mostly by droplets and contact with infected surfaces has invaded more than 200 countries and affected millions of people across the world. Pediatric cases in number were found to be negligible. But the highly contagious nature of the virus and the risk of spread from Pediatric cases are anything but negligible considering that the asymptomatic carriers are the most likely source of spread through community. ${ }^{1}$ Furthermore, the fact that children exhibit certain physiological intricacies and may not be able to describe their own symptoms or contact history makes it imperative to address the challenge of safeguarding, diagnosing early and treating this group.

The incubation period of COVID-19 is about 1 to 14 days but could extend up to 24 days. Most of the cases are asymptomatic or mild, but the elderly or those with underlying co-morbidities such as diabetes mellitus, hypertension, and chronic obstructive pulmonary disease are more likely to develop severe disease. ${ }^{2}$ A disproportionate burden of the disease has also been suggested with higher rates of poverty and within certain racial/ethnic groups, the scenario having been linked to living conditions, work circumstances, underlying health conditions, and lower access to care. ${ }^{3}$ There was an initial lack of data on children with COVID-19 across the globe in the previously reported studies. This was attributed to the children staying at home in the period of the beginning of the outbreak with lesser outdoor activities and lesser international travel. Since then, a steadily growing number of studies have focused on COVID-19, but limited data is available on epidemiological features, the diverse clinical manifestations, and transmission patterns of children with COVID-19, more so in India.

In this study, we prospectively recorded and evaluated the epidemiological and clinical characteristics of fifty children admitted to our tertiary care center with COVID-19 infection diagnosed by real-time polymerase chain reaction (RT-PCR). Early observations of a disease in a pandemic in different populations are crucial in improving the understanding of its physiologic behaviors, identifying associated risks, assessing the efficacy of the time-tested interventions and augmenting the awareness of clinicians as well as the masses in general about the myriad clinical profiles of an evolving pathogen. Such data thus also plays a pivotal role in guiding public health policymaking; hence this study to understand and help pick up these children early in routine Pediatric practice.

\section{Materials And Methods:}

This was a cross-sectional study conducted in a dedicated Pediatric COVID-19 center, Pune, Maharashtra state, India between $1^{\text {st }}$ April 2020 and $20^{\text {th }}$ May 2020. Prior approval was taken from the institutional ethics committee. Children between one month and 18 years of age who tested positive by the RT- PCR technique for nasopharyngeal swab were included in the study. Written and informed consent was obtained from the parents. Detailed information on demographic data, travel, contact, living conditions and overcrowding, symptoms, presence of co-morbid conditions were taken. All children were examined systematically and categorized to degree of severity based on pre-existing criteria. Baseline laboratory 
parameters (Complete Hemogram and C-reactive protein) were evaluated and repeated as required. Chest radiograph was done where indicated in the presence of fever or respiratory system involvement including disproportionately increased respiratory rates, chest retractions, and presence of adventitious sounds on auscultation or oxygen saturation $\left(\mathrm{SpO}_{2}\right)$ less than $94 \%$ in room air. Children were managed based on severity of illness as per hospital protocol for COVID-19. The children were reviewed daily up to discharge and changes in disease pattern, if any, were recorded. Discharge was decided as per prescribed Indian Council of Medical Research (ICMR) guidelines which until 10th May 2020 stated that asymptomatic children who tested negative for two nasopharyngeal swabs taken 24 hours apart after day 14 of illness were fit for discharge. After 10th May, discharge criteria were changed as per revised ICMR and Ministry of Health and Family Welfare (MoHFW) guidelines stating that asymptomatic children could be discharged after day 10 of illness without repeating nasopharyngeal swabs.

Definitions used:

Severity of illness was defined as in Table. 1

Overcrowding: Persons per room criteria have been used for judging the presence of overcrowding. ${ }^{4}$

Standard age-appropriate ranges for laboratory parameters as per Nelson Textbook of Pediatrics, $21^{\text {st }}$ Edition, were considered as normal. ${ }^{5}$

Statistical Analysis: Continuous variables were described as means and standard deviations; categorical variables were expressed as counts or percentages. At the end of sample size collection, the data was analyzed using the Statistical Package for Social Sciences (SPSS) software version 25.0.

\section{Results:}

A total of 50 children who tested positive for COVID-19 by RT-PCR were included in the study. Of these, 28 (56\%) were male. The mean (SD) age of all children was $6.95(5.22)$ years. $15(30 \%)$ of the children were in the age group of 0 to 2 years. There was history of close contact with family members with COVID-19 in $45(90 \%)$ children, while the remaining five $(10 \%)$ had no positive contacts. Of those 45 children, 42 had positive family members with mild illness, while three had family members with severe illness. Travel history to affected area was documented in only one (2\%) child (Table. 2). The region where children were hailing from was marked on the map of Pune to ascertain the areas with local transmission. It was noticed that $41(82 \%)$ of the cases hailed from containment zones in Pune (Figure. 1).

$29(58 \%)$ children were asymptomatic while $20(40 \%)$ and one (2\%) had mild and moderate symptoms respectively. In symptomatic children, fever was the chief complaint in $17(54 \%)$. Cough was present in eight (16\%), sore throat in seven (14\%), myalgia in four (8\%), diarrhea in two (4\%), headache in two (4\%) while one $(2 \%)$ child each had a rash and conjunctivitis. None of the children had hypoxemia measured by pulse oximeter. Only one (2\%) child had history of simple febrile seizures and one (2\%) child had underlying Type I diabetes mellitus who presented with diabetic ketoacidosis. The remaining 48 (96\%) 
were free of any co-morbidities. 49 (98\%) children had BCG scar. Immunization was complete in 32 (64\%) of the children as per universal immunization program.

The mean (SD) CRP of all the children was 10.98 (23.90). Mean (SD) Neutrophil-Lymphocyte-Ratio (NLR), Lymphocyte-Monocyte-Ratio (LMR), Platelet-Lymphocyte Ratio (PLR) were $0.78(0.48), 8.81(4.88)$, 82.36 (34.31) respectively (Table. 3 ). Chest radiograph was done in 20 symptomatic children. It was found to be normal in 18 , while two showed bilateral lower zone haziness.

\section{Discussion:}

In the early stages of the COVID-19 pandemic, the Pediatric data from across the globe stated a milder illness in children contracting the infection. As the pandemic runs its course, there are increasing concerns over the palpable threat of unidentified risks to children. In our study, we have witnessed a pattern similar to what has been previously described in other continents. However, the seemingly anonymous risk of an evolving disease pattern that could change course to a more life-threatening illness must be addressed based on such epidemiological and clinical data. The prime intention is to ensure an improved perception of the disease and better vigilance in handling it and containing its spread.

As of midnight, 25th May 2020, India had already recorded a total of 138,845 cases of COVID-19 with Maharashtra state leading the pack with number of cases accounting for $36.17 \%(50,231)$ of the total. Of these, children up to the age of 20 years account to only $10.54 \%$. Pune had a total of 443 cases were less than 20 years of age, with one recorded death.

Majority of the children in this study were detected in the government declared containment zones of Pune thus highlighting the significance of improving vigilance while attending to children coming from these areas. Majority of the children reported exposure to a positive close contact, a family member in most cases, indicating the current community transmission considering that $98 \%$ of children had no history of travel.

About two-third children met the criteria for residing in an overcrowded home thus highlighting the increased risk of transmission of SARS-CoV-2 in lower socio-economic groups with them carrying a disproportionate burden of the disease. Though the disease was seen in all age groups (Table 3), children less than five years of age accounted for $48 \%$ of all the cases. This can be attributed to the inability of this age group to comprehend and follow social distancing norms and the need for parents to constantly handle the children to attend to their dispositions.

About $58 \%$ of the children were asymptomatic and were detected as a part of screening when one of the family members tested positive indicating the covert nature of the virus. $40 \%$ were mildly symptomatic. Pediatric observational studies published early in the pandemic across China in February 2020 reported similar findings with fever being the most common symptom followed by cough and sore throat. ${ }^{6,7,8}$ However, as the pandemic progressed, newer 'atypical' manifestations were witnessed across different continents in the form of cutaneous exanthems, ${ }^{9,10}$ encephalitis, ${ }^{11,12}$ and myocarditis. ${ }^{13,14}$ 
In this study, all 50 (100\%) cases recovered completely with no morbidities. The adult COVID-19 mortality rate worldwide is $6.2 \%$ at present, with the mortality rate in children less than 18 years being much lesser at $<1 \% .{ }^{15}$ Various hypotheses have been suggested to explain the milder course of disease in children as compared to adults starting with constant exposure to multiple viral infections which helps the immune system response when infected with SARS-CoV-2. Children as opposed to adults have lesser comorbidities and healthier respiratory tracts. ${ }^{16}$ SARS-CoV-2 uses nasal angiotensin-converting enzyme-2 (ACE2) as a portal of entry to host. ${ }^{17}$ Lower ACE2 expression in nasal cavity may also help explain why COVID-19 is less prevalent in children. ${ }^{18}$

Almost all children in our study were vaccinated with BCG and $64 \%$ of them were completely vaccinated according to universal immunization program. Immunization of children with BCG is also thought to confer protection against the virus. Adults with COVID-19 have been found to have lymphopenia and reduced number of cytotoxic CD8+ T cells ${ }^{19}$ which as per some studies may be prevented by BCG vaccination induced stimulation of the CD4+ and CD8+ T-cell capabilities thus helping in destroying the virus-infected cells. ${ }^{20}$ However, countries like Iceland where BCG is not a part of routine vaccination policy have not seen significant morbidity or mortality in COVID-19, questioning the cross protectivity of BCG vaccine in SARS-CoV-2 infection. ${ }^{21}$ The available epidemiologic data has also formed a base for postulation of the Rubella component of MMR vaccine conferring protection against SARSCoV-2 infection. Also, the previous consideration of live measles vaccine as a base for other Coronavirus vaccines including SARS due to possible cross-over reactivity has formed the basis to encourage further research on the role of MMR against SARS-CoV-2. ${ }^{22}$

Malnutrition has been deemed a risk factor in adult COVID-19. ${ }^{23}$ In children, malnutrition is known to foster infections; however in this study, majority of the children were well nourished with respect to weight for age criteria. Also, only one ( $2 \%$ ) child had underlying Type I Diabetes Mellitus and rest were free of co-morbidities thus maybe reducing the burden of severe disease.

The hematological profile of adult with COVID-19 has demonstrated leucopenia with associated neutrophilia, lymphopenia, eosinopenia and thrombocytopenia. Also, higher Neutrophil-to-Lymphocyte ratios (NLR), Lymphocyte-to-Monocyte Ratios (LMR) and Platelet-to-Lymphocyte ratios (PLR) have been associated with severe disease and used for prognostication. ${ }^{24,25,26,27}$ Leucopenia, however, was seen in only three $(6 \%)$ of our children and there was no evidence of lymphopenia, thrombocytopenia or eosinopenia. Low NLR, LMR and PLR seen in our study correlated with asymptomatic or milder form of disease.

High CRP values have now become synonymous with severe COVID-19 infection among adults as seen in majority of the studies. ${ }^{28,29,30}$ Mean CRP in our study was found to be $10.98 \mathrm{mg} / \mathrm{dl}$. CRP as high as $153.77 \mathrm{mg} / \mathrm{dl}$ were seen in asymptomatic children while CRP as low as $4.59 \mathrm{mg} / \mathrm{dl}$ was seen in the severe case suggesting a milder immune response. Trends in CRP values may be used as a surrogate of inflammation in COVID-19 infection. 
Early studies from China stated that despite COVID-19 pneumonia in children being mild, chest computed tomography (CT) scan can present with characteristic changes of subpleural ground-glass opacities and consolidations of lung with surrounding halo. ${ }^{31}$ Early detection of lung lesions on CT as an alternative for diagnosis to the COVID-19 nucleic acid test from pharyngeal swab samples due to lack of adequate sensitivity was also proposed. In our study, we did not perform CT chest for any children. However, of the 20 children for whom a chest radiograph was done in view of persistent fever and cough, only one showed minimal lower zone infiltrates (<50\%) despite normal respiratory examination and oxygen saturation.

Repeat RT-PCR of nasopharyngeal swab was done on day 14 and 15 to check for infectivity status of the child. All the children except one were tested negative by RT-PCR for both the days. For the child who tested positive for one swab, a repeat swab was negative after three days, thus indicating that clearance of viral load may vary in different individuals. Similar findings were seen in other studies as well. ${ }^{32,33}$ The degree of infectivity of these individuals after 14 days remains questionable as RT-PCR detects genetic fragments of the virus and cannot distinguish between dead or live virus. ${ }^{34}$ In such scenarios, doing a viral culture may be the plausible method of detecting live virus and demonstrating continued infectivity. As performing a viral culture is difficult and requires advanced laboratory facilities, using GeneXpert platform with Ct values $\geq 24$ may also be beneficial for predicting lack of infectivity. ${ }^{35}$

Recently an alarming rise in the number of Pediatric and adolescent Kawasaki Disease and a multisystemic hyper-inflammatory syndrome associated with COVID-19 requiring admission to intensive care units have been reported in Europe as well as North America as the pandemic has progressed. ${ }^{36,37,}$ 38 An acute onset illness accompanied by a hyperinflammatory syndrome, leading to multi-organ failure and shock has been described. Initial hypotheses suggest association with COVID-19 either as a direct manifestation or an antibody positive post-infectious immune mediated response based on initial laboratory testing. The management in these cases included anti-inflammatory therapy, parenteral immunoglobulin and steroids. This makes it imperative to characterize this particular syndrome and its risk factors, to understand causality, and devise therapeutic strategies.

In conclusion, all age groups remain vulnerable to COVID-19. Our study re-iterates the milder disease pattern in children with COVID-19 in the early phase of the pandemic with majority being asymptomatic and mildly symptomatic. The epidemiological pattern indicates an ongoing community transmission of the disease. With a high proportion of asymptomatic and mild cases there is difficulty in identifying pediatric patients with COVID-19 infection. Even asymptomatic and mildly symptomatic patients may have high CRP despite showing no leucopenia, lymphopenia or thrombocytopenia early in the disease and normal leucocyte indices. Chest radiographs are normal in most mild cases but may occasionally show occasional infiltrates despite no clinical findings. All these factors put together create a potentially precarious situation of ongoing unchecked community spread of the virus, thus laying the foundation for increasing severity of illness and post-infectious immune-mediated syndromes. Public health policies must hence be directed to ensuring safe social distancing amongst children and adolescents taking into 
consideration the re-opening of day-care centers and schools which may emerge as a source of an uncontrollable spread of disease once the lockdown is lifted.

Limitations of the study: Being a study in the initial phase of the pandemic with lockdown in place, it may not cover the entire spectrum of clinical presentations, severity and magnitude of SARS-CoV-2 in children from different geographical areas.

Key Message: Majority of COVID-19 cases in children are asymptomatic and mildly symptomatic

What is already known? There is no Indian data available in the pediatric population with respect to the epidemiological and clinical characteristics of COVID-19.

What this study adds? Majority of Indian children with COVID-19 have a milder course of disease in the initial stages of the pandemic.

\section{Declarations:}

The authors of the preprint submission "Epidemiological and clinical characteristics of COVID19 in Indian children in the initial phase of the pandemic: A cross-sectional study" declare no competing interest.

\section{References:}

1. Riou J, Althaus CL. Pattern of early human-to-human transmission of Wuhan 2019 novel coronavirus (2019-nCoV), December 2019 to January 2020. Euro Surveill. 2020;25:7-11.

2. Zhu N, Zhang D, Wang W, et al. A novel coronavirus from patients with pneumonia in China, 2019. N Engl J Med. 2020;382:727-733.

3. Coronavirus Disease 2019 (COVID-19) [Internet]. Centers for Disease Control and Prevention. 2020 [cited 27 May 2020]. Available from: https://www.cdc.gov/coronavirus/2019-ncov/need-extraprecautions/racial-ethnic-minorities.html

4. Park K. Park's textbook of preventive and social medicine. 23rd ed. Jabalpur: Bhanot; 2015.p. 758

5. Kliegman, R., Stanton, B., St. Geme, J., Schor, N., Behrman, R. and Nelson, W., 2016. Nelson Textbook Of Pediatrics. 20th ed. Canada: Elsevier, pp.3464-73.

6. Qiu H, Wu J, Hong L, Luo Y, Song Q, Chen D. Clinical and epidemiological features of 36 children with coronavirus disease 2019 (COVID-19) in Zhejiang, China: an observational cohort study. The Lancet Infectious Diseases. 2020 Mar 25.

7. Cai J, Xu J, Lin D, Xu L, Qu Z, Zhang Y, Zhang H, Jia R, Wang X, Ge Y, Xia A. A Case Series of children with 2019 novel coronavirus infection: clinical and epidemiological features. Clinical Infectious Diseases. 2020 Feb 28.

8. Liu W, Zhang Q, Chen J, Xiang R, Song H, Shu S, Chen L, Liang L, Zhou J, You L, Wu P. Detection of Covid-19 in children in early January 2020 in Wuhan, China. New England Journal of Medicine. 2020 
Apr 2;382(14):1370-1.

9. Galván Casas C, Català A, Carretero Hernández G, Rodríguez-Jiménez P, Fernández Nieto $D$, Rodríguez-Villa Lario A, Navarro Fernández I, Ruiz-Villaverde R, Falkenhain D, Llamas Velasco M, García-Gavín J. Classification of the cutaneous manifestations of COVID-19: a rapid prospective nationwide consensus study in Spain with 375 cases. British Journal of Dermatology. 2020 Apr.

10. Recalcati S. Cutaneous manifestations in COVID-19: a first perspective. Journal of the European Academy of Dermatology and Venereology. 2020 Mar 26.

11. McAbee GN, Brosgol Y, Pavlakis S, Agha R, Gaffoor M. Encephalitis Associated with COVID-19 Infection in an 11 Year-Old Child. Pediatric Neurology. 2020 Apr 24.

12. Poyiadji N, Shahin G, Noujaim D, Stone M, Patel S, Griffith B. COVID-19-associated acute hemorrhagic necrotizing encephalopathy: CT and MRI features. Radiology. 2020 Mar 31:201187.

13. Inciardi RM, Lupi L, Zaccone G, Italia L, Raffo M, Tomasoni D, Cani DS, Cerini M, Farina D, Gavazzi E, Maroldi R. Cardiac involvement in a patient with coronavirus disease 2019 (COVID-19). JAMA cardiology. 2020 Mar 27.

14. Bonow RO, Fonarow GC, O'Gara PT, Yancy CW. Association of coronavirus disease 2019 (COVID-19) with myocardial injury and mortality. JAMA cardiology. 2020 Mar 27.

15. nyc.gov. 2020. COVID-19: Data Summary - NYC Health. [online] Available at: <https://www1.nyc.gov/site/doh/covid/covid-19-data.page> [Accessed 27 May 2020].

16. Kliegman R.M., St Geme J.W., Blum N.J., Shah S.S., Takser R.C., Wilson K.M. Edition 20. Elsevier; Philadelphia, PA: 2020. Nelson textbook of pediatrics

17. Hoffmann M, Kleine-Weber H, Schroeder S, Krüger N, Herrler T, Erichsen S, Schiergens TS, Herrler G, Wu NH, Nitsche A, Müller MA. SARS-CoV-2 cell entry depends on ACE2 and TMPRSS2 and is blocked by a clinically proven protease inhibitor. Cell. 2020 Mar 5.

18. Dong Y, Mo X, Hu Y, Qi X, Jiang F, Jiang Z, Tong S. Epidemiology of COVID-19 among children in China. Pediatrics. 2020 Apr 1.

19. Bermejo-Martin JF, Almansa R, Menendez R, Mendez R, Kelvin DJ, Torres A. Lymphopenic community acquired pneumonia as signature of severe COVID- 19 infection. The Journal of infection. England; 2020.

20. Salman S, Salem ML. The mystery behind childhood sparing by COVID-19. International Journal of Cancer and Biomedical Research. 2020 Apr 1;5(1):11-3.

21. Szigeti R, Kellermayer D, Kellermayer R. BCG protects against COVID-19? A word of caution. medRxiv. 2020 Jan 1.

22. Bunyavanich S, Do A, Vicencio A. Nasal gene expression of angiotensin-converting enzyme 2 in children and adults. JAMA. 2020.

23. Li T, Zhang Y, Gong C, Wang J, Liu B, Shi L, Duan J. Prevalence of malnutrition and analysis of related factors in elderly patients with COVID-19 in Wuhan, China. European Journal of Clinical Nutrition. 2020 Apr 22:1-5. 
24. Liu J, Liu Y, Xiang P, Pu L, Xiong H, Li C, Zhang M, Tan J, Xu Y, Song R, Song M. Neutrophil-tolymphocyte ratio predicts severe illness patients with 2019 novel coronavirus in the early stage. MedRxiv. 2020 Jan 1.

25. Lagunas-Rangel FA. Neutrophil-to-lymphocyte ratio and lymphocyte-to-C-reactive protein ratio in patients with severe coronavirus disease 2019 (COVID-19): A meta-analysis. Journal of medical virology. 2020 Apr 3.

26. Yang AP, Liu J, Tao W, Li HM. The diagnostic and predictive role of NLR, d-NLR and PLR in COVID-19 patients. International immunopharmacology. 2020 Apr 13:106504.

27. Liu Y, Du X, Chen J, Jin Y, Peng L, Wang HH, Luo M, Chen L, Zhao Y. Neutrophil-to-lymphocyte ratio as an independent risk factor for mortality in hospitalized patients with COVID-19. Journal of Infection. 2020 Apr 10.

28. Ling W. C-reactive protein levels in the early stage of COVID-19. Medecine et maladies infectieuses. 2020 Mar 31.

29. Tan C, Huang Y, Shi F, Tan K, Ma Q, Chen Y, Jiang X, Li X. C-reactive protein correlates with CT findings and predicts severe COVID-19 early. Journal of medical virology. 2020 Apr 13.

30. Wang G, Wu C, Zhang Q, Wu F, Yu B, Lv J, Li Y, Li T, Zhang S, Wu C, Wu G. C-Reactive Protein Level May Predict the Risk of COVID-19 Aggravation. InOpen Forum Infectious Diseases 2020 May (Vol. 7, No. 5, p. ofaa153). US: Oxford University Press.

31. Xia W, Shao J, Guo Y, Peng X, Li Z, Hu D. Clinical and CT features in pediatric patients with COVID-19 infection: Different points from adults. Pediatric pulmonology. 2020 May;55(5):1169-74.

32. Lan L, Xu D, Ye G, Xia C, Wang S, Li Y, Xu H. Positive RT-PCR test results in patients recovered from COVID-19. Jama. 2020 Apr 21;323(15):1502-3.

33. Zhang B, Liu S, Dong Y, Zhang L, Zhong Q, Zou Y, Zhang S. Positive rectal swabs in young patients recovered from coronavirus disease 2019 (COVID-19). Journal of Infection. 2020 Apr 23.

34. Lauri A, Mariani PO. Potentials and limitations of molecular diagnostic methods in food safety. Genes \& nutrition. 2009 Mar 1;4(1):1-2.

35. Bullard J, Dust K, Funk D, Strong JE, Alexander D, Garnett L, Boodman C, Bello A, Hedley A, Schiffman Z, Doan K. Predicting infectious SARS-CoV-2 from diagnostic samples. Clinical Infectious Diseases. 2020 May 22.

36. Pediatric Intensive Care Society. PICS Statement: Increased number of reported cases of novel presentation of multi-system inflammatory disease. April 27, 2020. Available at https://picsociety.uk/wp-content/uploads/2020/04/PICS-statement-re-novel-KD-C19-presentation-v227042020.pdf

37. Verdoni L, Mazza A, Gervasoni A, Martelli L, Ruggeri M, Ciuffreda M, Bonanomi E, D'Antiga L. An outbreak of severe Kawasaki-like disease at the Italian epicentre of the SARS-CoV-2 epidemic: an observational cohort study. The Lancet. 2020 May 13.

38. Toubiana J, Poirault C, Corsia A, Bajolle F, Fourgeaud J, Angoulvant F, Debray A, Basmaci R, Salvador E, Biscardi S, Frange P. Outbreak of Kawasaki disease in children during COVID-19 pandemic: a 
prospective observational study in Paris, France. medRxiv. 2020 Jan 1.

\section{Tables}

TABLES

\begin{tabular}{|c|c|c|c|}
\hline Asymptomatic & Mild & Moderate & Severe \\
\hline $\begin{array}{l}\text { No clinical } \\
\text { symptoms and } \\
\text { signs } \\
\mathrm{SpO}_{2}>94 \% \text { in } \\
\text { room air }\end{array}$ & $\begin{array}{l}\text { Any of the following: Fever, sore throat, cough, fatigue, } \\
\text { myalgia, rash, nasal congestion. } \\
\text { Gastrointestinal symptoms such as vomiting, loose stools and } \\
\text { pain in abdomen } \\
\text { SPO } 2>94 \% \text { in room air with age appropriate respiratory rate } \\
\text { and no adventitious sounds on auscultation and no abnormality } \\
\text { on chest radiograph }\end{array}$ & $\begin{array}{l}\text { All symptoms of } \\
\text { mild category } \\
\text { PLUS any two of } \\
\text { the following: } \\
\mathrm{SpO}_{2} \text { between } 90 \% \\
\text { - 94\% in room air } \\
\text { Tachycardia, } \\
\text { Tachypnea } \\
\text { Presence of } \\
\text { adventitious sounds } \\
\text { with infiltrates } \\
\text { on auscultation } \\
\text { Abnormal chest }\end{array}$ & $\begin{array}{l}\text { All symptoms of moderate category } \\
\text { PLUS any one of the following: } \\
\mathrm{SpO}_{2}<90 \% \text { in room air } \\
\text { Severe tachypnea or bradypnea } \\
\text { with presence of adventitious } \\
\text { sounds on auscultation } \\
\text { Persistent disproportionate } \\
\text { tachycardia or tachyarrhythmia } \\
\text { Abnormal chest radiograph with } \\
\text { infiltrates }>50 \% \\
\text { Evidence of poor perfusion with or } \\
\text { without hypotension } \\
\text { GCS score < } 10\end{array}$ \\
\hline
\end{tabular}

Table 1) Severity of illness 


\begin{tabular}{|c|c|}
\hline Parameters & $\mathrm{n}=$ Value $(\%)$ \\
\hline \multicolumn{2}{|l|}{ Sex } \\
\hline Male & $28(56)$ \\
\hline Female & $22(44)$ \\
\hline \multicolumn{2}{|l|}{ Distribution of children according to age (years) } \\
\hline 1 month to $\leq 5$ years & $24(48)$ \\
\hline$>5$ to $\leq 10$ years & $12(24)$ \\
\hline$>10$ to $\leq 15$ years & $11(22)$ \\
\hline$>15$ to 18 years & $3(6)$ \\
\hline Appropriate Weight-for-age ( $3^{\text {rd }}$ to $97^{\text {th }}$ centile) & $45(90)$ \\
\hline History of contact with patient of COVID- 19 & $45(90)$ \\
\hline Travel History to affected area & $1(2)$ \\
\hline Overcrowding & $33(66)$ \\
\hline \multicolumn{2}{|l|}{ Severity of Illness } \\
\hline Asymptomatic & $29(58)$ \\
\hline Mild & $20(40)$ \\
\hline Moderate & $1(2)$ \\
\hline Severe & $0(0)$ \\
\hline \multicolumn{2}{|l|}{ Symptoms } \\
\hline Fever & $17(34)$ \\
\hline Cough & $8(16)$ \\
\hline Sore Throat & $7(14)$ \\
\hline Myalgia & $4(8)$ \\
\hline
\end{tabular}




\begin{tabular}{|c|c|}
\hline Diarrhea & $2(4)$ \\
\hline Headache & $2(4)$ \\
\hline Rash & $1(2)$ \\
\hline Conjunctivitis & $1(2)$ \\
\hline \multicolumn{2}{|l|}{ Immunization status } \\
\hline BCG & $49(98)$ \\
\hline Age appropriate vaccination as per universal immunization program & $32(64)$ \\
\hline \multicolumn{2}{|l|}{ Associated Co-morbidities } \\
\hline None & $48(96)$ \\
\hline Simple Febrile Seizures & $1(2)$ \\
\hline Type I diabetes mellitus & $1(2)$ \\
\hline Cured & $50(100)$ \\
\hline
\end{tabular}

Table 2) Epidemiological and clinical characteristics of children 


\begin{tabular}{|c|c|c|c|c|}
\hline Parameter & Mean & Standard Deviation & Minimum & Maximum \\
\hline Hemoglobin $(\mathrm{g} / \mathrm{dl})$ & 12.00 & 1.74 & 7.6 & 16.6 \\
\hline Total Leucocyte Count (TLC) (/cumm) & 8863.83 & 3727.21 & 3300 & 19300 \\
\hline Absolute Neutrophil count (/cumm) & 2982.26 & 1500.56 & 696 & 7350 \\
\hline Absolute Lymphocyte count (/cumm) & 4973.38 & 3092.61 & 1248 & 15826 \\
\hline Absolute Monocyte count (/cumm) & 584.17 & 202.24 & 156 & 1071 \\
\hline Absolute Eosinophil count (/cumm) & 307.64 & 402.28 & 43 & 2280 \\
\hline CRP (mg/dl) & 10.98 & 23.90 & $<2.8$ & 153.77 \\
\hline NLR & 0.78 & 0.48 & 0.10 & 2.25 \\
\hline LMR & 8.81 & 4.88 & 2.13 & 27.00 \\
\hline PLR & 82.36 & 34.31 & 26.79 & 170.54 \\
\hline Leucopenia & \multicolumn{4}{|c|}{$3(6.00 \%)$} \\
\hline
\end{tabular}

Table 3) Laboratory investigations of children (TLC- Total Leucocyte count, CRP- C-Reactive proteins, NLR- Neutrophil-Lymphocyte-Ratio, LMR-

Lymphocyte-Monocyte-Ratio, PLR-Platelet-Lymphocyte Ratio), Leucopenia<4000cells/cumm, Lymphopenia <1000cells/cumm, Thrombocytopenia $<1,50,000$ cells/cumm, Eosinopenia <10/cumm)

Figures 


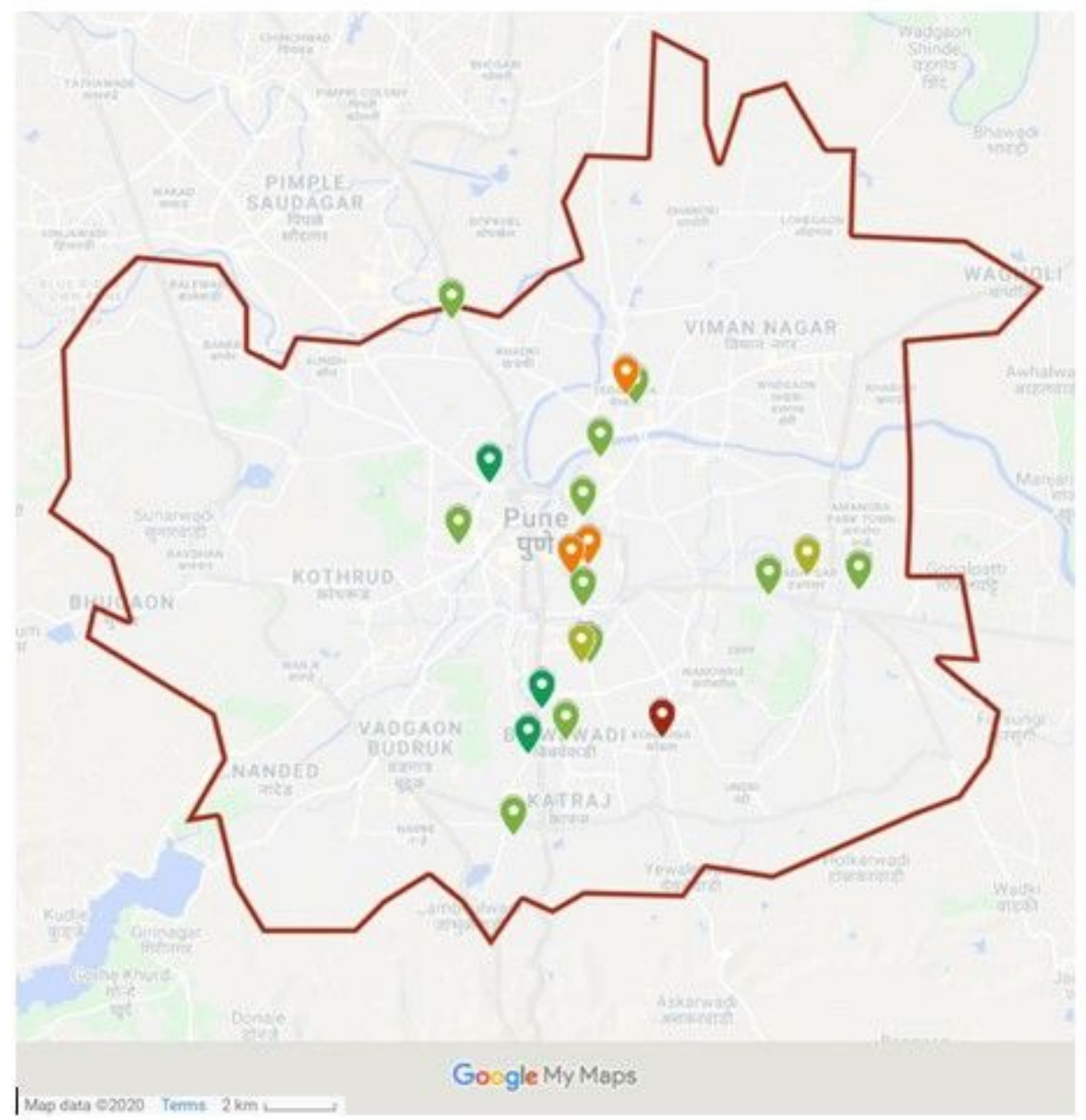

Figure 1

Fig. 1) Map of Pune with areas of endemicity [Color of the marker indicates the number of cases from that zone (Red- $\geq 8$ cases, Orange- 5 to 7 cases, Dark green- 3 to 4 cases, Light green- $\leq 2$ cases)] (Courtesy: Map data @2020: Google) 